\section{(B) OPEN ACCESS}

\title{
Sexually transmitted infection testing and self-reported diagnoses among a community sample of men who have sex with men, in Scotland
}

\author{
Lisa M McDaid, ${ }^{1}$ Jessica Li, ${ }^{1}$ Christina Knussen, ${ }^{2}$ Paul Flowers ${ }^{2}$
}

\begin{abstract}
Additional data are published online only. To view these files please visit the journal online (http://dx.doi.org/10.1136/ sextrans-2012-050605)

${ }^{1} \mathrm{MRC} / \mathrm{CSO}$ Social and Public Health Sciences Unit, Medical Research Council, Glasgow, UK ${ }^{2}$ Department of Psychology and Allied Health Sciences, School of Health and Life Sciences, Glasgow Caledonian University, Glasgow, UK
\end{abstract}

\section{Correspondence to} Dr Lisa M McDaid, MRC/CSO

Social and Public Health Sciences Unit, Medical Research Council, 4 Lilybank Gardens, Glasgow G12 8RZ, UK; I.mcdaid@sphsu.mrc.ac.uk

Accepted 3 September 2012 Published Online First 5 October 2012

\begin{abstract}
Introduction To examine sexually transmitted infection (STI) testing and self-reported diagnoses among men who have sex with men (MSM), in Scotland.

Methods Cross-sectional survey of seven Glasgow gay bars in July 2010 ( $n=822,62 \%$ response rate); 693 are included in the analyses.

Results $81.8 \%$ reported ever having had an STI test; $37.4 \%$ had tested in the previous 6 months; $13.2 \%$ reported having an STI in the previous 12 months. The adjusted odds of having ever tested were significantly higher for men who had $6+$ sexual partners in the previous 12 months (adjusted $\mathrm{OR}=2.66$ ), a maximum sexual health knowledge score (2.23), and had talked to an outreach worker/participated in counselling (1.96), and lower for men reporting any high-risk unprotected anal intercourse (UAl) in the previous 12 months (0.51). Adjusted odds of recent testing were higher for men who had $6+$ sexual partners (2.10), talked to an outreach worker/participated in counselling (1.66), maximum sexual health knowledge (1.59), and higher condom use knowledge (1.04), and lower for men aged $\geq 25$ years (0.46). Adjusted odds of having had an STI in the previous 12 months were higher for men who had $6+$ sexual partners (3.96) and any high-risk UAI in the previous 12 months (2.24) and lower for men aged $\geq 25$ years $(0.57)$.
\end{abstract}

Conclusions STI testing rates were relatively high, yet still below the minimum recommended for MSM at high risk. Consideration should be given to initiating recall systems for men who test positive for STIs, and to developing behavioural interventions which seek to address STI transmission.

\section{INTRODUCTION}

In addition to being the principal group at greatest risk of acquiring HIV in the UK, ${ }^{1}$ men who have sex with men (MSM) are disproportionately affected by a range of sexually transmitted infections (STIs), particularly syphilis and gonorrhoea. ${ }^{2}$ Increases in STI diagnoses have been widely reported, and have accompanied, and been associated with, increases in sexual risk behaviour and HIV testing among MSM since the 1990s. ${ }^{3-7}$ The incidence, prevalence and testing behaviours associated with HIV have merited much more attention than those associated with other STIs. However, the European MSM Internet Survey (EMIS) reported that rates of STI testing in the previous 12 months were $44 \%$ in the UK sample, and ranged from $15 \%$ to $53 \%$ overall. ${ }^{8}$ With moves to increase the frequency of, and essentially normalise, HIV testing among MSM (as part of regular sexual health screening), understanding the possible determinants of STI testing merits further attention.

At the UK level, there is inconsistency in guidance concerning the frequency of STI testing. Currently, the Health Protection Agency suggests that MSM have an HIV and STI screen at least annually, and more frequently if 'elevated risk' is reported. ${ }^{2}$ However, the British Association for Sexual Health and HIV (BASHH) guidelines recommend testing up to every 3 months for people 'at highest risk' of HIV infection. ${ }^{9}$ In Scotland, STI testing among MSM is advised to be repeated every 6-12 months for those 'at ongoing risk' ${ }^{10}$ Critically, there is no consensus concerning the parameters of how to define those at 'highest risk' or 'on-going risk'.

It is in this context that this paper addresses STI testing and experiences of risk. Identifying the factors associated with testing, and also experience of STIs, will enable more effective targeting of STI (and HIV) prevention efforts. We examine the factors associated with ever having had an STI test, recent STI testing, and, because of the high correlation between STI symptoms and testing behaviour, self-reported experience of STIs.

\section{METHODS}

The Make Your Position Clear (MYPC) mass media campaign aimed to promote regular sexual health and HIV testing every 6 months, and the use of appropriate condoms and water-based lubricant among gay and bisexual men in West Scotland. It ran from October 2009 to July 2010, and as part of its evaluation in July 2010, we conducted a cross-sectional survey of MSM from seven commercial gay bars in Glasgow using a form of time and location sampling. Bars were surveyed at two different time points, in the early (19:00-21:00) and late evening (21:00-23:00) hours. No bar was visited twice in the same evening. At the end of the survey, each bar had been visited at both time points on each day of the week. A team of temporary fieldworkers was trained and employed to distribute and collect anonymous, self-completed questionnaires in the bars. All men present or entering the venue were approached to complete a questionnaire. Ethical approval was granted by the psychology ethics subcommittee at Glasgow Caledonian University.

Questionnaires included demographics, sexual behaviour in the previous 12 months (number of 
sexual, anal and unprotected anal intercourse (UAI) partners), HIV and STI testing history (including recency of testing), and experience of STIs in the previous 12 months. To avoid issues of overlap between groups within number of sexual partners and anal sex partners, number of sexual partners was considered to best represent the risk of STI transmission on the basis that most STIs can be transmitted or acquired through means other than just anal sex (eg, through oral sex) and was, therefore, used in lieu of anal sex partners. A measure of 'high-risk' UAI was created, and includes men who reported any one of the following three behaviours: UAI with two or more partners, UAI with casual partners and/or UAI with unknown/discordant partners in the previous 12 months. Respondents were asked about contact with health improvement interventions in the previous 12 months (picked up a sexual health leaflet in bar, club or sauna; looked for safer sex/sexual health information on the internet; obtained free condoms from a bar/club sauna or the internet; talked to an outreach worker in a bar/ club or sauna; or participated in one-to-one or group counselling sessions on sexual health or HIV prevention).

Psychosocial factors relating to sexual health included measures of safer sex norms (eight items, higher score=stronger safer sex norms, $\alpha=0.61$ ), an attitude and norm of contemporary condom use scale (10 items, higher score $=$ stronger norm, $\alpha=0.82$ ), and barebacking norms (four items, higher score=greater acceptance of barebacking, $\alpha=0.59$ ). In all cases, a mean of contributing items was taken, with possible scores ranging from 1 to 5 . Two knowledge scales were included in the questionnaire: knowledge relating to correct condom use, and knowledge relating to sexual health (primarily HIV/STI testing). The condom knowledge scale included eight items, and scores were computed for all respondents who had attempted at least seven of the eight questions $(n=777)$. Scores ranged between -16 and +16 , with a mean of $7.78(\mathrm{SD}=6.98)$. The sexual health knowledge scale was based on four items, and the overall score was computed in the same way as that for the condom knowledge scale. Respondents had to have attempted at least three out of the four items to be given a score $(n=766)$, and scores ranged between -8 and +8 . Since $70.8 \%(n=542)$ gained the maximum score, the variable was dichotomised for further analysis, and those who gained the maximum score were compared with those who did not. See appendix 1 for full description of the psychosocial and knowledge scales.

The sample consisted of 822 men (response rate 62.6\%). Men with missing data on the STI testing variables, or who were not Scottish residents $(n=129)$ were excluded from the analyses. For bivariate comparisons, $\chi^{2}$ and $t$ tests were used. Factors significant at the bivariate level ( $p$ value $<0.05$ ) were entered into three separate multivariate logistic regression models for STI testing (ever and in the previous 6 months) and STI experience using the default method (Forced Entry Method) in SPSS V.15.0 for Windows. These models adjusted for factors related to STI testing or experience, and were used to estimate OR and 95\% CI. STI testing was dichotomised as follows: ever had an STI test (yes vs no); recency of STI test (less than 6 months ago vs. more than 6 months ago, or never). Number of sexual partners was dichotomised ( $0-5$ vs $6+$ partners), and HIV status was excluded because of the small numbers in the HIV-positive and untested categories.

\section{RESULTS}

\section{Sample characteristics}

Sample characteristics are shown in table 1. The average age of men sampled was 33 years (range $18-68, S D=10.35$ ), and most

Table 1 Sample characteristics $(n=693)$

\begin{tabular}{|c|c|c|}
\hline & $\mathbf{N}$ & $\%$ \\
\hline \multicolumn{3}{|l|}{ STI testing and experience } \\
\hline \multicolumn{3}{|l|}{ Ever had STI test } \\
\hline Never had STI test & 126 & 18.2 \\
\hline Had STI test & 567 & 81.8 \\
\hline \multicolumn{3}{|l|}{ Recency of STI test } \\
\hline In the previous 6 months & 259 & 37.4 \\
\hline Between 6 and 12 months ago & 115 & 16.6 \\
\hline Over 12 months ago & 193 & 27.8 \\
\hline Never had an STI test & 126 & 18.2 \\
\hline \multicolumn{3}{|l|}{ STI } \\
\hline Not had STI in previous 12 month & 594 & 86.8 \\
\hline Had STI in previous 12 months & 90 & 13.2 \\
\hline \multicolumn{3}{|l|}{ Demographics } \\
\hline \multicolumn{3}{|l|}{ Age } \\
\hline$<25$ years & 195 & 28.3 \\
\hline $25+$ years & 493 & 71.7 \\
\hline \multicolumn{3}{|l|}{ Frequency of gay scene use } \\
\hline Once a month or less & 156 & 22.7 \\
\hline $2-3$ times a month & 211 & 30.7 \\
\hline Once or more a week & 321 & 46.7 \\
\hline \multicolumn{3}{|l|}{ Employment } \\
\hline Employed or self-employed & 550 & 79.6 \\
\hline Unemployed, student, retired & 141 & 20.4 \\
\hline \multicolumn{3}{|l|}{ Area of residence } \\
\hline Rest of Scotland & 141 & 20.3 \\
\hline Glasgow & 552 & 79.7 \\
\hline \multicolumn{3}{|l|}{ Education } \\
\hline Secondary & 120 & 17.5 \\
\hline Further/vocational & 296 & 43.2 \\
\hline Degree/postgraduate & 269 & 39.3 \\
\hline \multicolumn{3}{|l|}{ HIV status } \\
\hline HIV tested and HIV-positive & 21 & 3.3 \\
\hline HIV tested and HIV-negative & 477 & 75.4 \\
\hline Never been tested & 135 & 21.3 \\
\hline \multicolumn{3}{|l|}{ Sexual behaviour in the previous 12 months } \\
\hline \multicolumn{3}{|l|}{ Number of sexual partners } \\
\hline 0 or 1 partner & 199 & 29.8 \\
\hline 2-5 partners & 247 & 37.0 \\
\hline $6-10$ partners & 92 & 13.8 \\
\hline $11+$ partners & 129 & 19.3 \\
\hline \multicolumn{3}{|l|}{ Any high-risk UAl } \\
\hline No & 444 & 64.1 \\
\hline Yes & 249 & 35.9 \\
\hline \multicolumn{3}{|c|}{ Contact with sexual health promotion in the previous 12 months } \\
\hline \multicolumn{3}{|c|}{ Obtained free condoms from a bar/club sauna or the internet } \\
\hline No & 157 & 23.2 \\
\hline Yes & 520 & 76.8 \\
\hline \multicolumn{3}{|c|}{$\begin{array}{l}\text { Picked up a sexual health leaflet in a bar/club/sauna, or looked for safer sex/sexual } \\
\text { health information on the internet }\end{array}$} \\
\hline No & 329 & 48.7 \\
\hline Yes & 346 & 51.3 \\
\hline \multicolumn{3}{|c|}{$\begin{array}{l}\text { Talked to an outreach worker in a bar/club or sauna or participated in one-to-one or } \\
\text { group counselling sessions on sexual health or HIV prevention }\end{array}$} \\
\hline No & 515 & 76.3 \\
\hline Yes & 160 & 23.7 \\
\hline \multicolumn{3}{|l|}{ Sexual health and condom use knowledge } \\
\hline Sexual health knowledge & & \\
\hline Less than maximum score & 197 & 29.0 \\
\hline Maximum score & 482 & 71.0 \\
\hline
\end{tabular}


Table 1 Continued

\begin{tabular}{lrr}
\hline & N & $\%$ \\
\hline & & \\
& Mean & SD \\
& 7.74 & 7.02 \\
Condom use knowledge & & \\
Norms & 2.54 & 0.89 \\
$\quad$ Barebacking norm & 3.82 & 0.77 \\
$\quad$ Attitudes and norms towards contemporary condom use & 3.75 & 0.81 \\
$\begin{array}{l}\text { (ANCCU) } \\
\text { Safer sex norms }\end{array}$ & & \\
\hline $\begin{array}{l}\text { ANCCU, attitude and norm of contemporary condom use scale; STI, sexually transmitted } \\
\text { infection; UAl, unprotected anal intercourse. }\end{array}$ &
\end{tabular}

men visited the gay scene at least once a week. The majority were employed and educated beyond secondary level. Most were sexually active, and more than one-third reported any high-risk UAI in the previous 12 months. The majority reported that they were HIV-negative, and just over one in five had never been tested. Having obtained free condoms from a bar, club or the internet was the most frequently reported sexual health promotion activity, and most men surveyed had high sexual health and condom knowledge scores.

\section{STI testing and experience}

Overall, 567 men (81.8\%) reported ever having had an STI test. Only a little more than one-third of men had tested in the previous 6 months, while $16.6 \%$ had tested between 6 and 12 months ago, and $27.8 \%$ had tested over 12 months ago (table 1); $13.2 \%$ reported having had an STI in the previous 12 months.

STI testing was found to be highly associated with HIV testing. Among men who reported having had an STI test, $93.6 \%$ also reported having had an HIV test: $\left(\chi^{2}=344.76\right.$, $\mathrm{p}<0.001) ; 88.2 \%(\mathrm{n}=224)$ of men who had an STI test in the previous 6 months had had an HIV test in the previous 6 months $\left(\chi^{2}=391.85, p<0.001\right)$, and $91.3 \% \quad(n=335)$ of men who had had an STI test in the previous 12 months had had an HIV test in the previous 12 months $\left(\chi^{2}=369.62, p<0.001\right)$.

\section{Factors associated with STI testing and STI experience}

Tables 2-4 show the factors associated with STI testing and experience. The likelihood of ever having had an STI test was higher for men who: were aged $\geq 25$ years; were educated to degree/postgraduate level; reported $6+$ sexual partners and no high-risk UAI; picked up a sexual health leaflet in a bar, club or sauna, or looked for sex/sexual health information on the internet; talked to an outreach worker in a bar, club or sauna, or participated in one-to-one or group counselling sessions on sexual health or HIV prevention; had a high sexual health and condom knowledge; and had stronger condom norms (table 2).

The likelihood of having an STI test in the previous 6 months was higher for men who: were aged $<25$ years; were unemployed, a student, or retired; reported $6+$ sexual partners; talked to an outreach worker or participated in counselling; and had high sexual health and condom knowledge (table 3).

The likelihood of reporting an STI in the previous 12 months was higher for men who: were aged $<25$ years; visited the gay scene at least once week; reported $6+$ sexual partners and highrisk UAI; had greater acceptance of barebacking and weaker condom norms (table 4).

In multivariate analysis, the odds of ever having had an STI test remained significantly higher for men who had $6+$ sexual partners in the previous 12 months compared with men who had 0-5 partners, men who had a maximum sexual health knowledge score compared with men who had less than a maximum score, and men who talked to an outreach worker or participated in counselling on sexual health of HIV prevention. The odds were significantly lower for men who had reported any high-risk UAI in the previous 12 months (table 2).

The adjusted odds of having had an STI test in the previous 6 months remained significantly higher for men who had $6+$ sexual partners in the previous 12 months, men who had talked to an outreach worker or participated in counselling on sexual health or HIV prevention, men who had a maximum sexual health knowledge score compared with men who had less than the maximum score, and men who had higher condom use knowledge (table 3). By contrast, the odds of having an STI test in the previous 6 months were lower for men who were aged $\geq 25$ years.

The adjusted odds of having had an STI in the previous 12 months were higher for men who had $6+$ sexual partners and any high-risk UAI in the previous 12 months, and lower for men who were aged $\geq 25$ years (table 4 ).

Men aged $<25$ years were more likely to report high-risk UAI $\left(\chi^{2}=5.59, p=0.018\right)$, but there was no significant interaction between age and UAI in any of the regression models.

\section{DISCUSSION}

The majority of MSM who took part in the survey had had an STI test at some point in their lives, while one-third had tested in the previous 6 months; just over one in 10 had had an STI in the previous 12 months. Such high recent STI testing rates are not commonly reported, but one US study found $63.8 \%$ of MSM surveyed had tested in the previous 6 months, ${ }^{11}$ while a study of primary care clinics in Melbourne, Australia, found 6 monthly retesting rates of only $15 \%$ among higher-risk MSM. ${ }^{12}$ The EMIS Survey reported that rates of STI testing in the previous 12 months ranged from $15 \%$ in Slovakia to $53 \%$ in The Netherlands $44 \%$ in the UK) $;^{8}$ this compares with $70 \%$ in the Australian Gay Community Periodic Surveys. ${ }^{13}$ Rates of ever testing were also considerably lower in the Scottish and English samples of EMIS than in our survey (62\% and $71 \%$, respectively). ${ }^{14} 15$

First, some limitations of our data should be considered. It is important to note that only men who visited the venues surveyed had the opportunity to participate, and caution should be taken when generalising to the wider population of MSM. The anonymous nature of the survey prevents identification of men who could have completed the questionnaire more than once, but this is thought unlikely given the short timeframe of data collection and the training of fieldworkers to avoid this. Recall and reporting biases could affect underestimating or overestimating of actual levels of STI testing and experience. These analyses do not (and cannot) show whether the STI tests reported here are regular or frequent events, or whether they are proactively chosen as part of a sexual health screen, or are responsive to symptoms of STIs. Finally, the cross-sectional nature of the data precludes any analysis of causality.

Although the chance of having ever had an STI test increases over the life course, younger men (aged $<25$ years) were most likely to have had an STI test in the previous 6 months. They were also most likely to have had an STI in the previous 12 months (it remains unclear whether this correlation can be explained by opportunistic screening resulting in diagnosis of asymptomatic infection, or whether symptoms led to testing, although it should be noted that there is no opportunistic screening programme for chlamydia among young men in 
Table 2 Factors associated with ever having had an STI test among MSM in Scotland: $\mathrm{n}$ \%, unadjusted and multivariate logistic regression

\begin{tabular}{|c|c|c|c|c|c|c|c|c|}
\hline & $\begin{array}{l}\text { Never had an STI test }(n=126) \\
n(\%)\end{array}$ & $\begin{array}{l}\text { Had an STI test }(n=567) \\
n(\%)\end{array}$ & $\mathbf{O R}$ & $95 \% \mathrm{Cl}$ & p Value & AOR $(n=594)$ & $95 \% \mathrm{Cl}$ & p Value \\
\hline \multicolumn{9}{|l|}{ Demographics } \\
\hline$<25$ & $45(23.1)$ & $150(76.9)$ & 1 & & & 1 & & \\
\hline $25+$ & $81(16.4)$ & $412(83.6)$ & 1.53 & (1.01 to 2.30$)$ & 0.043 & 1.21 & (0.74 to 1.97$)$ & 0.447 \\
\hline \multicolumn{9}{|l|}{ Frequency of gay scene use } \\
\hline Once or more a week & $63(19.6)$ & $258(80.4)$ & 0.94 & (0.57 to 1.52$)$ & & & & \\
\hline \multicolumn{9}{|l|}{ Employment } \\
\hline Employed or self-employed & $98(17.8)$ & $452(82.2)$ & 1 & & & & & \\
\hline Unemployed, student, retired & 28 (19.9) & $113(80.1)$ & 0.88 & (0.55 to 1.40$)$ & 0.576 & & & \\
\hline \multicolumn{9}{|l|}{ Area of residence } \\
\hline Rest of Scotland & $33(23.4)$ & $108(76.6)$ & 1 & & & & & \\
\hline Further/vocational & $64(21.6)$ & $232(78.4)$ & 0.58 & (0.37 to 0.90$)$ & & 0.57 & (0.34 to 0.95$)$ & \\
\hline Degree/postgraduate & $37(13.8)$ & $232(86.2)$ & 1 & & 0.048 & 1 & & 0.096 \\
\hline \multicolumn{9}{|l|}{ HIV status* } \\
\hline HIV tested and HIV positive & $0(0.00)$ & $21(100.0)$ & & & & & & \\
\hline HIV tested and HIV negative & $20(4.2)$ & $457(95.8)$ & & & & & & \\
\hline Never been tested & $99(73.3)$ & $36(26.7)$ & & & & & & \\
\hline \multicolumn{9}{|c|}{ Sexual behaviour in the previous 12 months. } \\
\hline \multicolumn{9}{|l|}{ Number of sexual partners } \\
\hline $0-5$ partners & $96(21.5)$ & $350(78.5)$ & 1 & & & 1 & & \\
\hline $6+$ partners & $26(11.8)$ & $195(88.2)$ & 2.06 & (1.29 to 3.28$)$ & 0.002 & 2.66 & (1.58 to 4.50 ) & $<0.001$ \\
\hline \multicolumn{9}{|l|}{ Had any high-risk UAI } \\
\hline No & $66(14.9)$ & $378(85.1)$ & 1 & & & 1 & & \\
\hline Yes & $53(15.3)$ & $293(84.7)$ & 1.49 & (1.01 to 2.22 ) & 0.046 & 1.1 & (0.69 to 1.77 ) & 0.682 \\
\hline \multicolumn{9}{|c|}{ Talked to an outreach worker in a bar/club or sauna, or participated in one-to-one or group counselling sessions on sexual health or HIV prevention } \\
\hline No & $105(20.4)$ & $410(79.6)$ & 1 & & & 1 & & \\
\hline Yes & $17(10.6)$ & $143(89.4)$ & 2.15 & (1.25 to 3.72$)$ & 0.006 & 1.96 & (1.02 to 3.77$)$ & 0.044 \\
\hline \multicolumn{9}{|c|}{ Sexual health and condom use knowledge. } \\
\hline \multicolumn{9}{|l|}{ Sexual health knowledge score } \\
\hline Less than maximum score & $60(30.5)$ & $137(69.5)$ & 1 & & & 1 & & \\
\hline \multirow[t]{2}{*}{ Maximum score } & $62(12.9)$ & $420(87.1)$ & 2.97 & (1.98 to 4.44 ) & $<0.001$ & 2.23 & (1.38 to 3.61$)$ & 0.001 \\
\hline & Mean (SD) & Mean (SD) & & & & & & \\
\hline Condom knowledge & $5.58(7.57)$ & $8.21(6.82)$ & 1.05 & (1.02 to 1.08$)$ & $<0.001$ & 1.01 & (0.98 to 1.04 ) & 0.602 \\
\hline \multicolumn{9}{|l|}{ Norms } \\
\hline Mean of barebacking items & $2.61(0.92)$ & $2.52(0.89)$ & 0.89 & (0.71 to 1.11 ) & 0.304 & & & \\
\hline ANCCU norm scale & $3.67(0.78)$ & $3.85(0.76)$ & 1.33 & (1.04 to 1.69 ) & 0.023 & 1.26 & (0.93 to 1.70 ) & 0.132 \\
\hline Safer sex scale & $3.71(0.85)$ & $3.76(0.79)$ & 1.08 & (0.84 to 1.38$)$ & 0.554 & & & \\
\hline
\end{tabular}

${ }^{*}$ Not included in univariate and multivariate analyses because of inadequate cell counts.

ANCCU, attitude and norm of contemporary condom use scale; AOR, adjusted OR; MSM, men who have sex with men; STI, sexually transmitted infection; UAI, unprotected anal intercourse.

Scotland). Second, a clear pattern was observed in relation to sexual behaviour. Increased STI testing and diagnosis were observed among men reporting higher numbers of sexual partners in the previous 12 months; a finding also reported elsewhere. $^{12} 16$ The associations between sexual risk behaviour, testing and diagnosis are to some extent reassuring; those at risk are also the ones who are testing most often, perhaps because they have acquired STIs. However, with only around half of those at highest risk reporting testing in the previous 6 months, and men who reported high-risk UAI being less likely to have ever tested (but more likely to have tested positive for STIs), there is still some way to go to meet the minimum testing levels being recommended for MSM at risk, ${ }^{9}{ }^{10}$ particularly the every 3 months being recommended by 
Table 3 Factors associated with having had an STI test in the previous 6 months among MSM in Scotland: $n$, \%, unadjusted and multivariate logistic regression

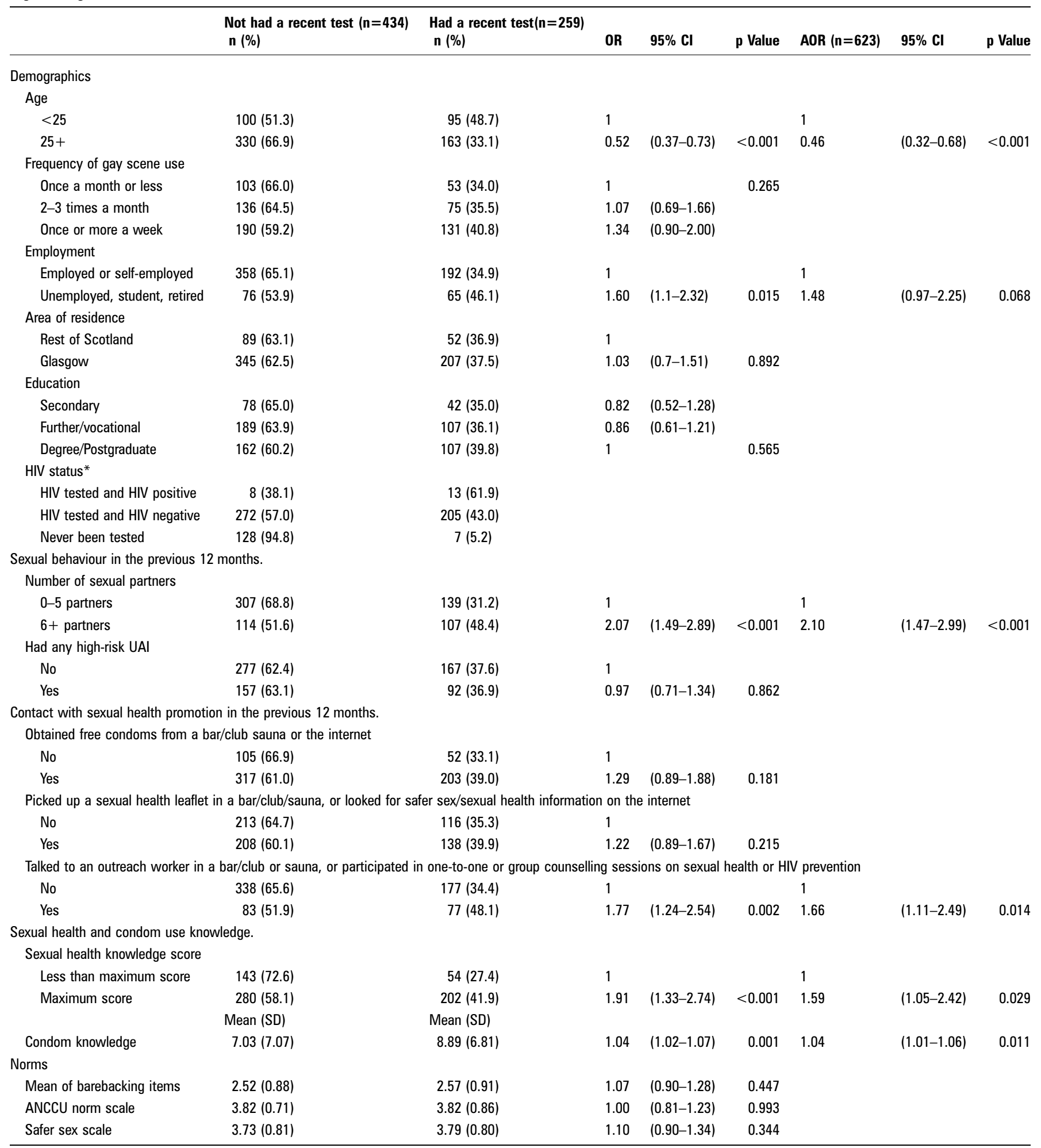

*Not included in univariate and multivariate analyses because of inadequate cell counts.

ANCCU, attitude and norm of contemporary condom use scale; AOR, adjusted OR; MSM, men who have sex with men; STI, sexually transmitted infection; UAI, unprotected anal intercourse.

BASHH. $^{9}$ Consideration should be given to initiating recall systems for men who test positive for STIs, and to promoting the uptake of regular opportunistic testing among those who have previously reported an STI. For instance, a recent UK study found such a system feasible, achieving high rescreening rates and identification of incident infections, ${ }^{17}$ while an Australian study found short message service reminders increased retesting among MSM. ${ }^{18}$ Equally, the use of venuebased testing (including those places and spaces in which men meet for sex) should be encouraged. ${ }^{19}$ 
Table 4 Factors associated with having had an STI in the previous 12 months among MSM in Scotland: n, \%, unadjusted and multivariate logistic regression

\begin{tabular}{|c|c|c|c|c|c|c|c|c|}
\hline & $\begin{array}{l}\text { Did not have an STI in } \\
\text { previous } 12 \text { months }(n=594) \\
n(\%)\end{array}$ & $\begin{array}{l}\text { Had an STI in previous } \\
12 \text { months }(n=90) \\
n(\%)\end{array}$ & $\mathbf{O R}$ & $95 \% \mathrm{Cl}$ & $\mathrm{p}$ value & AOR $(n=620)$ & $95 \% \mathrm{Cl}$ & p Value \\
\hline \multicolumn{9}{|l|}{ Age } \\
\hline$<25$ & $155(81.2)$ & $36(18.8)$ & 1 & & & 1 & & \\
\hline $25+$ & $435(89.1)$ & $53(10.9)$ & 0.53 & $(0.33-0.83)$ & 0.006 & 0.57 & $(0.34-0.97)$ & 0.037 \\
\hline 2-3 times a month & $184(88.5)$ & $24(11.5)$ & 1.70 & $(0.80-3.58)$ & & 1.48 & $(0.65-3.35)$ & \\
\hline Once or more a week & $263(83.0)$ & $54(17.0)$ & 2.67 & $(1.35-5.27)$ & & 2.06 & $(0.96-4.41)$ & \\
\hline \multicolumn{9}{|l|}{ Employment } \\
\hline Employed or self-employed & $476(87.7)$ & $67(12.3)$ & 1 & & & & & \\
\hline Unemployed, student, retired & $117(84.2)$ & $22(15.8)$ & 1.34 & $(0.79-2.25)$ & 0.277 & & & \\
\hline \multicolumn{9}{|l|}{ Area of residence } \\
\hline Secondary & $97(84.3)$ & $18(15.7)$ & 1.27 & $(0.68-2.35)$ & & & & \\
\hline Further/vocational & $258(87.5)$ & $37(12.5)$ & 0.98 & $(0.60-1.61)$ & & & & \\
\hline Degree/postgraduate & $232(87.2)$ & $34(12.8)$ & 1 & & 0.686 & & & \\
\hline \multicolumn{9}{|l|}{ HIV status* } \\
\hline HIV tested and HIV positive & $16(76.2)$ & $5(23.8)$ & & & & & & \\
\hline HIV tested and HIV negative & $401(84.8)$ & $72(15.2)$ & & & & & & \\
\hline Never been tested & $127(95.5)$ & $6(4.5)$ & & & & & & \\
\hline \multicolumn{9}{|c|}{ Sexual behaviour in the previous 12 months. } \\
\hline \multicolumn{9}{|l|}{ Number of sexual partners } \\
\hline $0-5$ partners & $408(92.5)$ & $33(7.5)$ & 1 & & & 1 & & \\
\hline $6+$ partners & $164(75.2)$ & $54(24.8)$ & 4.07 & $(2.55-6.51)$ & $<0.001$ & 3.96 & $(2.34-6.71)$ & $<0.001$ \\
\hline \multicolumn{9}{|l|}{ Had any high-risk UAI } \\
\hline No & $277(85.2)$ & $48(14.8)$ & 1 & & & & & \\
\hline Yes & $305(89.2)$ & $37(10.8)$ & 0.70 & $(0.44-1.12)$ & 0.128 & & & \\
\hline \multicolumn{9}{|c|}{ Talked to an outreach worker in a bar/club or sauna, or participated in one-to-one or group counselling sessions on sexual health or HIV prevention } \\
\hline No & $446(88.0)$ & $61(12.0)$ & 1 & & & & & \\
\hline Yes & $134(83.8)$ & $26(16.3)$ & 1.42 & $(0.86-2.33)$ & 0.169 & & & \\
\hline \multicolumn{9}{|c|}{ Sexual health and condom use knowledge. } \\
\hline \multicolumn{9}{|l|}{ Sexual health knowledge score } \\
\hline Less than maximum score & $167(86.5)$ & $26(13.5)$ & 1 & & & & & \\
\hline \multirow[t]{2}{*}{ Maximum score } & $418(87.1)$ & $62(12.9)$ & 0.95 & $(0.58-1.56)$ & 0.847 & & & \\
\hline & Mean (SD) & Mean (SD) & & & & & & \\
\hline Condom knowledge & $7.74(6.88)$ & $7.65(8.12)$ & 1.00 & $(0.97-1.03)$ & 0.907 & & & \\
\hline \multicolumn{9}{|l|}{ Norms } \\
\hline Mean of barebacking items & $2.48(0.87)$ & $2.86(0.98)$ & 1.59 & $(1.24-2.05)$ & $<0.001$ & 1.08 & $(0.75-1.56)$ & 0.669 \\
\hline ANCCU norm scale & $3.87(0.73)$ & $3.56(0.92)$ & 0.63 & $(0.48-0.83)$ & 0.001 & 0.67 & $(0.45-1.00)$ & 0.053 \\
\hline Safer sex scale & $3.76(0.79)$ & $3.69(0.87)$ & 0.90 & $(0.68-1.19)$ & 0.453 & & & \\
\hline
\end{tabular}

*Not included in univariate and multivariate analyses because of inadequate cell counts.

ANCCU, attitude and norm of contemporary condom use scale; AOR, adjusted OR; MSM, men who have sex with men; STI, sexually transmitted infection; UAl, unprotected anal intercourse.

Ever and recent STI testing were higher among men with greater levels of sexual health knowledge, suggesting a possible association between testing and what could be termed 'sexual health literacy'. Recent testing was also higher among men who reported that they had talked to an outreach worker or participated in one-to-one or group counselling on sexual health or HIV prevention in the previous 12 months. Although causality cannot be assessed, this suggests continuing engagement with sexual health promotion should remain a key component of combination approaches to prevention. It is 
important to note that the data reported in this paper were collected as part of an evaluation of the MYPC mass media campaign, aimed at promoting positive sexual health behaviours in MSM. Indeed, MYPC was the latest in a series of health improvement campaigns aimed at increasing STI and HIV testing among MSM in Scotland, and the recent increases in HIV testing, ${ }^{6}{ }^{7}$ and the now relatively high proportions reporting recent STI (and $\mathrm{HIV}^{20}$ ) testing, could reflect the effectiveness of these campaigns. However, the causality of such associations cannot be assessed, and a recent Cochrane review concluded there was little evidence of an increase in STI testing from social marketing campaigns with MSM. ${ }^{21}$ Although norms for condom use did not remain significant in the multivariate models for ever having an STI test and having had an STI, it is critical that we consider and understand how the effectiveness of interventions is mediated by, or dependent upon, normative factors at the community level. ${ }^{22}$

There was a strong association between STI and HIV testing, and it is important to consider the secondary use of sexual health screening as a means of facilitating opportunities for HIV testing (with HIV-negative men) and prevention (with HIV-positive and HIV-negative men). General sexual health testing could offer a means of increasing the frequency and uptake of HIV testing (since HIV testing is routinely being offered within sexual health screening), potentially vital to the success of biomedical interventions such as treatment as a prevention, ${ }^{23}$ if these were to be widely adopted. Equally regular STI testing among HIV-positive men should also be thought of as a core component of treatment as prevention; coinfection with STIs is known to increase infectivity among people living with HIV, even among those on antiretroviral treatment (ART). ${ }^{2}$

From a prevention viewpoint, it is important to develop and evaluate a range of interventions which focus upon STI testing, and develop a more nuanced appreciation of the similarities and differences between behaviours associated with HIV and other STIs. Areas of divergence may be a useful starting point, such as examining those who test for STIs but opt out of HIV testing, or in contrast, considering STI-specific sexual and health behaviours, such as oral sex, numbers of sexual partners, anilingus, vaccination uptake, adherence to antibiotics and antivirals, and attendance at repeat clinical visits (for test of cure). Equally in terms of convergence, there is increasing scope to explore the transferability of interventions relating to HIV testing to that of STI testing, and to develop behavioural interventions which seek to address STI transmission (rather than testing per se).

\section{Key messages}

- In a survey of men who have sex with men, in Glasgow most men had had a sexually transmitted infection (STI) test at some point across their sexual careers, and over one-third had tested in the previous 6 months.

- Younger men, those with higher numbers of sexual partners and greater sexual health literacy were more likely to have tested recently.

- Recall systems for those who test positive for STls should be explored.

- The use of sexual health screening as a means of facilitating opportunities for frequent HIV testing and HIV prevention demands further research.
Acknowledgements The authors thank the survey staff and fieldworkers in each city, the venue managers, their staff and all the men who agreed to participate in the survey.

Contributors LM, CK and PF designed the study. CK cleaned and prepared the data and $\mathrm{JL}$ conducted the analyses. LM devised the paper and wrote the first draft. All authors contributed to subsequent drafts and approved the final version of the manuscript.

Funding The 2010 survey was funded by NHS Greater Glasgow \& Clyde, NHS Ayrshire \& Arran and NHS Lanarkshire. The UK Medical Research Council funds Dr Lisa McDaid and Jessica Li.

\section{Competing interests None.}

Ethics approval Psychology ethics subcommittee at Glasgow Caledonian University.

Provenance and peer review Not commissioned; externally peer reviewed.

Data sharing statement Data sharing requests should be directed to the study Cl, Prof Paul Flowers, P.Flowers@gcu.ac.uk.

Open Access This is an Open Access article distributed in accordance with the Creative Commons Attribution Non Commercial (CC BY-NC 3.0) license, which permits others to distribute, remix, adapt, build upon this work non-commercially, and license their derivative works on different terms, provided the original work is properly cited and the use is non-commercial. See: http://creativecommons.org/licenses/by-nc/3.0/

\section{REFERENCES}

1. Health Protection Agency. HIV in the United Kingdom: 2011 Report. London: Health Protection Services, 2011.

2. Health Protection Agency. Sexually transmitted infections in men who have sex with men in the UK: 2011 Report. London: Health Protection Agency, 2011.

3. Macdonald N, Dougan S, McGarrigle CA, et al. Recent trends in diagnoses of HIV and other sexually transmitted infections in England and Wales among men who have sex with men. Sex Transm Infect 2004;80:492-7.

4. Elford J. Changing patterns of sexual behaviour in the era of highly active antiretroviral therapy. Curr Opin Infect Dis 2006;19:26-32.

5. Sullivan PS, Hamouda O, Delpech V, et al. Reemergence of the HIV epidemic among men who have sex with men in North America, Western Europe, and Australia, 1996-2005. Ann Epidemiol 2009;19:423-31.

6. McDaid LM, Hart GJ. Increased HIV testing and reduced undiagnosed infection among gay men in Scotland, 2005-8: support for the opt-out testing policy? Sex Transm Infect 2011;87:221-4.

7. Williamson LM, Flowers $\mathrm{P}$, Knussen $\mathrm{C}$, et al. HIV testing trends among gay men in Scotland, UK (1996-2005): implications for HIV testing policies and prevention. Sex Transm Infect 2009;85:550-4.

8. Quinlan M, Donlon S, McCarthy D, et al. The European MSM Internet Survey (EMIS): Community Report 2, 2011. http://www.emis-project.eu/community-report-2 (accessed 24 Feb 2012).

9. Clutterbuck DJ, Flowers P, Barber T, et al. United Kingdom national guidelines on safer sex advice. London: The Clinical Effectiveness Group of the British Association for Sexual Health and HIV and British HIV Association, 2012.

10. Scottish Government. The sexual health and blood borne virus framework: 2011-15. Edinburgh: Scottish Government, 2011.

11. Rosenberger JG, Van Der Pol B, Herbenick D, et al. HIV and bacterial STI testing among men who have sex with men in the USA [published abstract]. Sex Transm Infect 2011;87(Suppl 1):A48.

12. Guy R, Goller JL, Spelman T, et al. Does the frequency of HIV and STI testing among men who have sex with men in primary care adhere with Australian guidelines? Sex Transm Infect 2010:86:371-6.

13. Zablotska IB, Kippax S, Grulich A, et al. Behavioural surveillance among gay men in Australia: methods, findings and policy implications for the prevention of HIV and other sexually transmissible infections. Sex Health 2011;8:272-9.

14. Sigma Research. All Scotland (EMIS) 2010 summary report. London: Sigma Research. http://www.sigmaresearch.org.uk/gmss/year/yr2010 (accessed 24 Feb 2012).

15. Sigma Research. All England 2010 summary report. London: Sigma Research. http://www.sigmaresearch.org.uk/gmss/year/yr2010 (accessed 24 Feb 2012).

16. Zablotska IB, Imrie J, Bourne C, et al. Improvements in sexual health testing among gay men in Sydney, Australia, 2003-2007. Int J STD AIDS 2008;19:758-60.

17. Harte D, Mercey D, Jarman J, et al. Is the recall of men who have sex with men (MSM) diagnosed as having bacterial sexually transmitted infections (STIS) for re-screening a feasible and effective strategy? Sex Transm Infect 2011:87:577-82.

18. Bourne C, Knight V, Guy R, et al. Short message service reminder intervention doubles sexually transmitted infection/HIV re-testing rates among men who have sex with men. Sex Transm Infect 2011;87:229-31.

19. National Institute for Health and Clinical Excellence. NICE public health guidance 34: increasing the uptake of HIV testing to reduce undiagnosed infection and prevent transmission among men who have sex with men. London: National Institute for Health and Clinical Excellence, 2011. 
20. Flowers $\mathbf{P}$, Knussen C, Li J, et al. Has testing been normalised? An analysis of changes in barriers to HIV testing among men who have sex with men between 2000 and 2010 in Scotland, UK. HIV Med Published Online First: 30 Aug 2012. doi:10.1111/j.1468-1293.2012.01041.x.

21. Wei C, Herrick A, Raymond HF, et al. Social marketing interventions to increase HIV/ STI testing uptake among men who have sex with men and male-to-female transgender women. Cochrane Database Syst Rev Published Online First: 7 Sep 2012. doi:10.1111/j.1468-1293.2012.01041.x

22. Flowers $\mathbf{P}$, Knussen C, McDaid LM, et al. Weakening of safer sex community norms amongst Scottish gay men. (Forthcoming).

23. Wagner BG, Kahn JS, Blower S. Should we try to eliminate HIV epidemics by using a 'Test and Treat' strategy? AIDS 2010;24:775-6. 